\title{
Rural- Urban Migrants as Second Class Workers; China\& Arab Case
}

\author{
SIHAM GOURIDA \\ PhD Candidate, School of Economic \& Management, Nanchang University
}

\begin{abstract}
This paper analyzes the details \& the nature of the work before and after the migration decision; how did the workers migrated and how did they find the jobs in the city? How is the living and working conditions in the city and how it was in the village? How much is their consumption and saving from the income in the city? Do the migrants get all their rights and interests in the city? All these questions will be discussed here, the research is based on the data I have got from the questionnaire and in depth interviews which has adopted and conducted on November 2013 among the rural migrants in Nanchang city (China), Cairo (Egypt) and Djelfa city in Algeria. The comparative study will be made between the research regions.

KEYWORD: Rural migrants; China; Algeria; Egypt
\end{abstract}

\section{INTRODUCTION}

Different reasons pushed the rural people to leave the village to the city in aim to find job and get better life; the low income, low education level, bad living conditions in the village, and the unsatisfactory in the work..Etc all these factors forced the rural migrants to accept any job opportunity available in the city even in dirty, dangerous and sometimes without any insurance.

The main idea of this paper was created to assume the phenomena of the rural-urban labor migration worldwide and specially in developing countries such as China and Arab countries. The research will discuss the working status and conditions, evaluation of the previous migration experience by the migrants. etc It is based on several principal ideas; starting by analyzing the phenomenon of the rural labor migration in China and comparing and discuss also the working conditions situation of those migrants. After that the research goes with more details in the rural-urban migration in China and Arab countries. And analyze these cases starting from the economics and sociology perspectives such as the migrants' wages, their working conditions and the other benefits through some tools such as the questionnaire survey, in-depth interviews and introduce some migrants' profiles to get more details about the main motivator factors to migrate and the consequences of the migration' decision on the migrants themselves and their families.

\section{BASIC KNOWLEDGE ABOUT THE CASE}

\subsection{How did the migrants find their current jobs}

How did the rural migrants find their jobs in the cities? The figure 1 below introduces the results I have got from the questionnaire; about 23.8 percent of the Algerian migrants interviewed in the questionnaire said that they got the current job through their relatives in the city, while the percentage of the Chinese migrants for the same question is 20.9 percent and the results of Egypt case is totally different; a high percentage $(41.3 \%)$ of the migrants got help from relatives in the city to find the current jobs. About 35.6 percent of the Algerian migrants got help from their friends, 23.1percent for the Chinese migrants and the higher percentage is found in the Egyptian respondents; 42.3 percent found the current jobs through their friends.

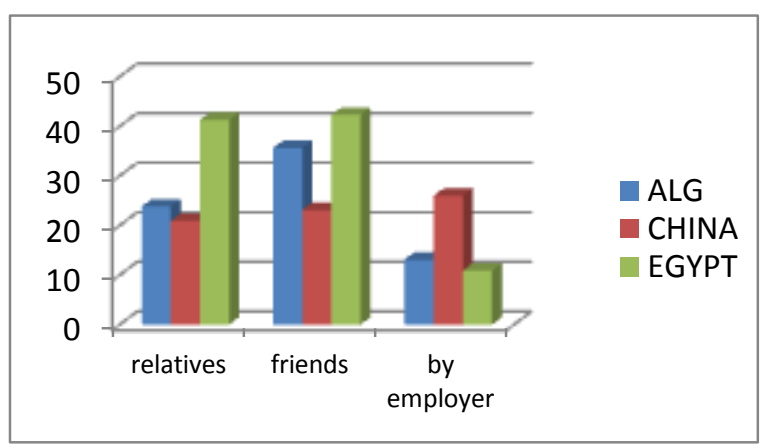

Figure 1 how did the rural migrants got their current work?

Source: Source: made by author depends on the questionnaire results Nov2013. 
The third option that the respondents were given was through the employers, hiring interviews...etc high percentage among the three countries was found in China (20\%), Algerian migrants come secondly with 13.1 percent and only 10.9 percent from the Egyptian migrant workers said that they got the current job through the employment.

\subsection{Evaluation of the previous migrating jobs in the city}

When I started my research about rural to urban migration phenomenon among three examples of developing countries I thought the working turnover would be high among the rural migrants in the three regions. But when go ahead on the questionnaire and study I saw that most of the rural migrants prefer to continue in the same work field and in some cases when they move to another job the mains reason for that decision was the differences in the wages or better working conditions.

I asked the migrants through my questionnaire to evaluate their previous jobs in the city; I gave three options to select one; remained same, got better or got worse. The results I've got are shown in the figure 2 below. About $85 \%$ of the Egyptian migrants said that their job conditions since the first time they arrived to Cairo got better even the situation in Egypt is not stable after the $25^{\text {th }}$ Jan evolution, while almost same percentages in both Algeria \& China (about 45\%) mentioned this evaluation. lower percentage for the three countries' migrants who said that the working condition got worse $4.5 \%, 13 \%$ and $15.6 \%$ for Egypt, China and Algeria, while about one fourth of the Chinese migrants mentioned that their jobs remained the same, they are doing same working tasks since they came to the city "Nanchang" even they changed the working positions from one place to another but the working conditions and wages remained the same, while only $4.4 \%$ of the Algerian migrants and $9.5 \%$ of the Egyptians said their jobs got worse.

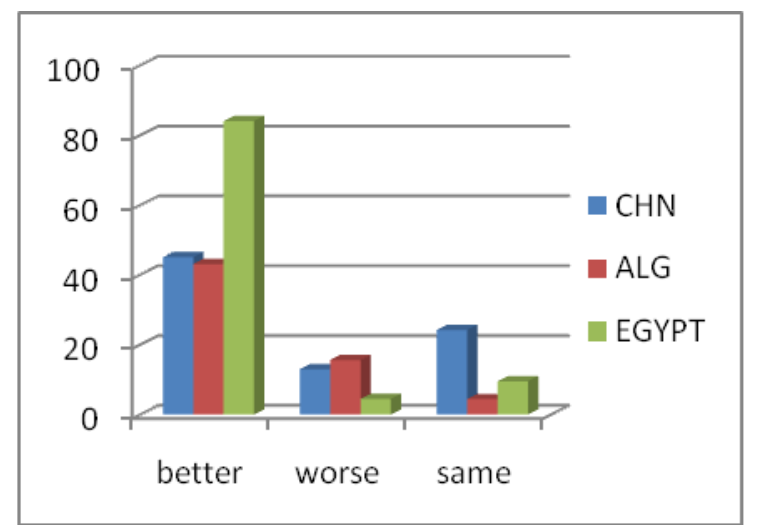

Figure 2 Evaluation of the previous migrating jobs in the city

Source: Source: made by author depends on the questionnaire results Nov2013.
The main problem about possible improvements in job status and type needs some further comment. By mainly targeting casual laborers and construction workers at their workplaces, hiring sites and coffeeshops, I naturally tended to exclude those who had made a qualitative shift to better jobs. However, from general knowledge and other conversations with informants, I saw that some movement out of the construction sector has taken place - more in the past than at present. Whether this is true "upward" mobility is doubtful, since the moves which can be observed are "horizontal" into parallel informalsector fields, such as street-vending, working in the cemeteries, or as assistants in workshops.

Chinese migrant workers, desperate to escape the bad working conditions, are traveling in precisely the opposite direction. Over the past three decades, millions of them have left home to find work, two thirds going beyond their home provinces and millions overseas undertaking what is justifiably called the largest migration in human history. As Taiwanese journalist Hsiao-Hung Pai persuasively demonstrates in Scattered Sand, many members of this "new mobile proletariat," despite 80-hour work weeks and backbreaking labor, are becoming virtual untouchables, caught between a blighted countryside and hostile, unattainable cities (Liang, LiQing. 2012) despite powering the country's economic growth; they receive a pittance of the proceeds. The number of "mass incidents," many of the migrants" work, grows by the year. The "floating population" (liudong renkou in Chinese) is the specter haunting China. Ross Perlin (2012)

\section{EVALUATION OF WORK DYNAMICS}

\subsection{M ode of working contract}

The working contract mode introduce the types of working based; whether the migrants work in a long, medium or short term contracts or they are working based on daily/short period tasks. It's normal in three countries to find some rural migrants waiting near to the wholesale markets to get any daily based tasks and I found this situation more common in both Egyptian and Algerian case than in China. The higher percentages of working based on contract were found in China, Algeria than Egypt perceptively.

From the table below, it s clear that the high percentage of Chinese migrants about $75 \%$ mentioned that they are working based on medium term contracts and about $20.6 \%$ (103 cases) said that their working contracts for or less than a year and only 1.2 percent work within long term contracts more than 5years.

In Algeria the situation is totally different; about 43.8 percent said their jobs are based on tasks, actually it's well known among the rural migrants in 
the different countries that the task based work is potentially more profitable than the daily-based, but less regular, some migrants labors prefer to do some tasks for 3-4 hours once and got their wages, it's more flexible but in some cases they work one day and couldn't get any work in the next day, the dailybased work is for a fixed rate while the task based work is by bargaining and may lead to double the revenues of the daily-based work. On the other hand, daily-based work guarantees a fixed income for that day.

The percentage of short term contract for the Algerian rural migrants wash not so high (18.8percent) while about 25.6percent mentioned that they are working based on long term contracts (more than 5years) and only 6.9percent they got medium term working contracts. For the Egyptian migrants working mode; 56.7 percent of the rural labors their working contract is short term contracts and $26.4 \%$ based on tasks jobs while only 16.9 percent of them who got medium term contracts. It is important here to refer to a unique type of hiring that prevails among migrants who have solid family and social networks in Cairo “开罗” and for some villages - or a group of villages - in Upper Egypt there are well-known permanent focal points representing a concentration of old migrants and transitional migrants who refuse to be fully absorbed by the Cairo urban system. They live pretty much as if they are in their villages, keeping the same customs, norms, daily lifestyles, and traditions.

\subsection{Working days and daily working hours}

It is well know that the official working days in the three countries from five to six days per week (Friday in Egypt, Friday and Saturday in Algeria and Saturday, Sunday in China) with six to eight working hours per day. The common day for Muslims in Arabian Countries is Friday; in Egypt the Christian employees start work one hour later than their Muslim counterparts on Sunday to enable them to attend the Sunday prayer.

From the surveyed labors answers I found that the higher percentages for the two regions are divided almost the same way; most of the migrants in the three countries work from six to ten hours per day most work more than 8 hours- in china 92.8 percent work from six to ten hours, here I mentioned that most of the Chinese rural workers are working in construction and industrial zones which let them to work little hours than the Arabian migrants especially in Egypt -who worked more than eight hours per day. The percentages of both Algeria and Egypt for the same working hours are 64.4 and 67.7 percent respectively. No workers mentioned that they work more than ten hours per day in both of Algeria and China while about 13.9percent mentioned that in Egyptian case. Almost same percentage of the Arab labors in the two countries who work six hour or less, while about only7.8 percent for the Chinese migrants.

The task-based workers are likely to work more hours if they can find enough work to do. It is important here to refer to the underemployment problem in the government and the inflation of the number of government employees. The productivity of government workers in some sectors is less than one hour per day.

The rural migrants work is very hard, especially in task-based activities. Migrant workers in taskbased activities try to finish the task in the shortest time that they can. This is to return back to their focal point to be ready for another task. However, in some cases, their colleagues prohibit them to go to another job if they themselves did not get any work since the early morning. (UNFPA 2007).Daily work is not guaranteed. Some migrants work the seven days while some others may, if they are unlucky, work only one day per week. Reference in the questionnaire is made to the week that preceded the date of interview. Workers who work three days or less per week comprise 1.3 percent only.

The average working days per week is almost five (4.9 days to be exact). Multiplying average hours per day by average days per week gives average hours per week. Average hours per week are 41.7 hours which is 5.7 hours more than the average for government employees but 6.3 hours less than the average for the private sector employees (Zohry Ayman 2002).

For the working days we can see from the same table that most rural migrants couldn't get off days or enough rest, even for vacations; in china 85.4 percent got one off day max while the situation in Algeria is different almost 42 percent couldn't get off days or one day maximum per week and about 39.4 percent can get more than one day (two days same as the weekend off days in the country), in Egypt high percentage (91percent) mentioned that they got more than one day without work; as I mentioned above that most migrants prefer task based works which means their working days is not stable, for sometimes in one day they can earn as two days money and couldn't get any job opportunity in the next day. 
Table 1 the work characteristics of migrant workers in three countries

\begin{tabular}{|l|c|c|c|}
\hline \multirow{2}{*}{} & \multicolumn{3}{|c|}{ Percentage \% } \\
\cline { 2 - 4 } & CHN & ALG & EGY \\
\hline Work contract mode & & & \\
Less than 1 year & 20.6 & 18.8 & $\mathbf{5 6 . 7}$ \\
From 1-5years & $\mathbf{7 4 . 9}$ & 6.9 & 16.9 \\
More than 5 years & 1.2 & 25.6 & 0 \\
Based on tasks & 0 & $\mathbf{4 3 . 8}$ & 26.4 \\
\hline Daily working hours & & & \\
6 hours and less & 7.8 & 18.1 & 18.4 \\
6to 10 hours & $\mathbf{9 2 . 8}$ & $\mathbf{6 4 . 4}$ & $\mathbf{6 7 . 7}$ \\
More than 10 hours & 0 & 0 & 13.9 \\
\hline Working days per week & & & \\
No off days/ max 1 day & 85.4 & 41.9 & 9.0 \\
Off days more than 1 & 14.6 & 39.4 & 91.0 \\
\hline Daily wage on average (USD) & & & \\
Less than 8 & 1.6 & 35.0 & 40.3 \\
8 to 10 & 87.2 & 46.9 & 37.8 \\
More than 10 & 11.2 & 3.1 & 5.0 \\
\hline Receiving wage mode & & & \\
Daily & 0 & 5.6 & 40.8 \\
weekly & 3.0 & 2.5 & 34.8 \\
monthly & 86.6 & 75.0 & 24.4 \\
\hline Total & $\mathbf{1 0 0}$ & $\mathbf{1 0 0}$ & $\mathbf{1 0 0}$ \\
\hline
\end{tabular}

Source: Source: made by author depends on the questionnaire results Nov2013.

\subsection{Daily wages and receiving wages modes}

In my study and before I start the analyzing the results I've got from the respondents I want to mention here that I choose the UDS as a common unit for the wages amounts and without excluding the differences in the exchange rates $(1 \mathrm{USD}=6$ Yuan, 1USD=75 ALG Dinar, 1 USD= 7.15EG Pound) and the questionnaire results are shown in the table 1 above.

Only eight Chinese migrants (about $1.6 \%$ ) out of my sample of 501 reported that their wages are less than 8 Dollars, while most of them $87.2 \%$ their wages are between eight and ten dollars and about $11.2 \%$ got more than 10 Dollars daily. Most of them $(86.6 \%)$ reported that they receive their wages monthly, while only $(3 \%)$ they receive their wages weekly.

The case in Arab countries is totally different; I found that in the two Arabian countries the percentages almost similar. In Algeria $46.9 \%$ got about eight to ten dollars as daily wage and $35 \%$ got less than eight dollars, while only $3.1 \%$ earn more than ten dollars as daily wage. Most of the Algerian workers I interviewed got their wages monthly and their jobs are more stable while only $2.5 \%$ and $5.6 \%$ got their wage weekly and daily basis.

For the Egyptian case; the highest percentage $40.8 \%$ receive their wage on daily basis and $34.8 \%$ they receive their wage weekly, while $24.4 \%$ who got monthly wages, those migrants are the luckiest among all migrants since they are guaranteed work opportunities for longer period of time in advance. Those migrants are closely tied to a contractor who guarantees this work for them. Advance payments and installments within the week and month are common in case of Egypt.

The wages of the Egyptian rural migrants are the lowest among the three countries that I made my study on, about $40.3 \%$ got less than eight dollars as daily wage and most mentioned that their wages are not stable due to the daily or task working basis, some days they earn some money while some days couldn't get any money, those who get eight to ten dollars as daily wage were $37.8 \%$ (76 respondents) while only $5 \%$ (10 cases) who get more than ten dollars as daily wage.

\subsection{The pending and saving percentages}

Questionnaire respondents were asked to give an approximate figure for the amount of money that they spend on living per day in general (the results are shown in table 2). In China; $74.9 \%$ (about375 respondents) spend less than $50 \%$ of their salary on daily costs, while $13 \%$ (66 migrants) spend between $50-70 \%$ from their salary on daily expenses. This means- as shown in figure above- that about $32 \%$ of the migrants can save between $25-50 \%$ of their wages, while $36 \%$ can save less than $25 \%$ from their wages, and only $7 \%$ of the migrants can save more than $50 \%$ of their wages.

Table 2 the percentages of spending and saving from the daily wages

\begin{tabular}{|c|c|c|c|c|}
\hline \multicolumn{1}{|c|}{} & CH & ALG & EGY \\
\hline \multirow{4}{*}{ Spending } & $\mathbf{0}$ & 12.0 & 24.4 & 10.0 \\
\cline { 2 - 5 } & Less 50\% & 74.9 & 40.6 & 71.1 \\
\cline { 2 - 5 } & $50-70 \%$ & 13.2 & 25.0 & 18.9 \\
\cline { 2 - 5 } & More than 70\% & 0 & 10.0 & 0 \\
\hline \multirow{4}{*}{ Saving } & $\mathbf{0}$ & $\mathbf{2 4 . 8}$ & 14.4 & 16.4 \\
\cline { 2 - 5 } & Less 25\% & $\mathbf{3 5 . 9}$ & 26.1 & 12.4 \\
\cline { 2 - 5 } & $25-50 \%$ & $\mathbf{3 2 . 1}$ & 10.0 & 53.7 \\
\cline { 2 - 5 } & More than 50\% & $\mathbf{7 . 2}$ & 10.6 & 17.4 \\
\cline { 2 - 5 } & I don't save anything & & 20.8 & \\
\hline
\end{tabular}

Source: Source: made by author depends on the questionnaire results Nov2013.

\section{CONCLUSIONS}

From this study and previous studies I found that the Migrants are less educated than the urban areas citizens. Also they are the poorest, and it is precisely this poverty, often linked to landless and large 
families, which motivated them to migrate. Also, they do not live a complete social life in the city. In case of Egypt for example; from the village point of view, a wife's fear of losing her husband in the urban environment perhaps encourages her to tie him with more children. One explanation for migrants' higher than expected fertility relates to the increased material well-being of migrants' remittances which guide to an increase of the financial input, migrants may feel able to have more children than they would have had without this extra income supplement.

It's normal and well known that the education level of the parents has a negative relation with the number of children -fertility- educated migrants have fewer children than non-educated migrants. The difference is more than one live child between the two groups. However, this comparison should only be taken as an indicator of the effect of education, rather than a hard fact, due to the few numbers of educated migrants (UN2005). For the same reason, calculating the mean number of children by wife's education is not possible due to the prevalence of illiteracy among migrants' wives. A further factor which compromises the significance of the educated versus non-educated figures of numbers of children is the age factor, for older migrants are the ones who tend to have both less education and (by virtue of their age) more children.(Zohry 2002)

A majority of people in China probably agree that the household registration system is archaic and unfair and that rural hukou holders working in the cities should be given greater access to schooling, social and medical welfare benefits. (SCC2012) However, there is also considerable resistance from urban residents to relaxation of restrictions. Urban governments often do not have the financial resources to expand provision of social services to include all migrant workers and their families. There is also resistance from the police to wholesale hukou reform, at least until an alternative system of national identity cards can be put in place that can ensure effective surveillance and tracking of criminals (State Council 2011). At present, hukou reform has been limited to piecemeal reform at the local level, with individual regions relaxing restrictions for certain rural migrant workers, in most cases those from the same province and those who have already made a demonstrable contribution to the local economy. (NESD2006-2010\&2011-2015) That approach seems destined to continue for the foreseeable future.

\section{REFERENCES}

[1] Liang, LiQing. They were born in cities, but they are confused. The new generation peasant workers are always on the road, Shanghai China News, 20 Feb 2012, <http://www.sh.chinanews.com/pageurl/20122201314417. html>, (05 April 2012).

[2] Ross Perlin (2012) Ghosts in the Machine: the story of China's Rural Migrants and Their Uncertain Future, article available on http://www.thedailybeast.com 12.10.12.

[3] State Council of China, Several Opinions regarding how to solve migrant workers issues 27 Mars 2006 <http://www.gov.cn/jrzg/2006-03/27/content_237644.htm> (21 Feb 2012).

[4] State Council, Development of Household registration reform, 2011, p1-3; http://www.gov.cn/zwgk/2012-02/23/ content_2075082.htm

[5] Zohry Ayman 2002 rural to urban labor migration; a study of Upper Egyptian laborers in Cairo. PhD dissertation, University of Sussex at Brighton.

[6] United Nations Population Fund (UNFPA) Peering into the dawn of an urban millennium;, State of world population 2007: Unleashing the potential of urban growth (UNFPA, 2007), available at: www.unfpa.org/swp/2007/english/introduction.html.

[7] United Nations publication. (2005) Population Challenges and Development Goals. ISBN 92-1-151411-8. New York.

[8] $11^{\text {th }}$ Five-Year Plan for National Economy and Social Development, 2006-2010. Retrieved from: http://www.china.org.cn/features/guideline/node_1156529. htm (05-12-2010).

[9] 12th Five-Year Plan for National Economy and Social Development, 2011-2015. Retrieved from: http://www.apcoworldwide.com/content/PDFs/Chinas_12th _Five-Year_Plan.pdf (28-01-2011). 